oestrogens and progestogens, urinary excretion of hormones during and after treatment with oestrogens and progestogens, effects of long and short term treatment, tumour growth, control of male fertility, and practical instructions for advising patients during treatment.

Coverage of these various topies is quite thorough, but the two to three year delay in publication has made some of the content rather dated. Thus epidemiological studies in the United Kingdom have definitely established that the use of oral contraceptives lcads to a small increase in thrombotic episodes. The book does not deal with this evidence, apart from a remark on page 230a. But remarkable from any standpoint is the sentence on page 257 which states that "there is no connection between treatment with ovulation inhibitors and an increase in the risk of thrombophlebitis. At least . . . the risk is no more incrcased than it would be by a new pregnancy". The two parts of this remark are mutually contradictory.

Many other points could be mentioned which seem misleading. Thus, on page 256 , the differences in reliability between combined and sequential oral contraceptives are said to be so small as to be "solely of academic interest". The usually accepted failure rates are, por 100 woman years, 0.3 and 5 , that is, a fifteen-fold difference. In discussing contraindications, the author considers hepatic cirrhosis and extensive liver damage as only relative contraindications to the use of oral contraceptives. In UK practice they are absolute. Whether these remarks originate from the author or the translator is not clear.

The book has a good bibliography of more than 500 papers. The references are listed alphabetically by author, and enverage, especially of the German literature, is good. There is an adequate subject index.

Considerod as a whole, this book is a failure, but this seerns not to be the fault of the author but of his unfortunate selection of translator and publisher. As it stands, the book is a good summary of knowledge on hormonal contraception up to 1967 . Some sections arc open to dispute, but not many. Unfortunately, the translation is so poor that much of the text is confusing, while the previously mentioned printing and textual errors make the book irritating. In a rapidly developing field, the primary task of a monograph is to present up to date trends and it is to be hoped that in any future edition of this book this will be borne in mind.

M. H. Briggs viously formulated problem might bo achieved and finally led to the so-called BCS theory, which integrates the two steps.

Most of the authors in these two volumes describe the state of superconductivity, and the refinements which have been achieved meanwhile. An introductory chapter is followed by twenty-one chapters which deal with the numerous achievements. It would be unfair to select one or another for minor criticism. Jointly, they form an cxcellent introduction for research physicists. The final chapter is entitled "Superconductivity in the Past and the Future" (15 pages only). Its author, P. W. Anderson, terminates it with ". . much of what I have said is ... opinion, rather than scientific truth"; and, indeed, it contains more with which I cannot agree than the rest of the book. Yet this short chapter is so much better than the rest that it is on a completely different level. It is the only section that is alive.

What, after my earlier praise, is wrong then with the rest of the toxt? Essentially, it is the authors' inbred approach which prevents them from recognizing a physical problem when it cannot be formulated in terms of their own particular mathematical method. One sot of problems-only touched on here and there--concerns magnitudes of transition temperatures, which can be linked to the question whether all non-ferromagnetie metals should become superconductors at sufficiently low temperatures. This requires trcatment of the electronclectron and electron-ion interactions by the same method, so that they can be compared-clearly a problem outside a specific theory of the superconductive state. More important, however, would be a classification of how many results, presented as a direct consequence of a very specific microscopic theory, can be obtained more generally, requiring the specific theory only to obtain the magnitude and behaviour of certain quantities affecting the more gencral results. Such clarification would also remove the fear of having to reform the whole building whon certain experimental features do not agrce with a specific microscopic theory -a foar which still seems to linger on, judging from the editor's remarks: ". . . should discourage all but the most fanatical opponents of ...".

On a still higher level, a separation of general from specific features should permit viewing the achievements within superconductivity in perspective and hence make them available to other fields. The impact, in particular that of macro quantization, may be considerable.

H. Fröнlich

\section{ORTHODOX SUPERCONDUCTIVITY}

\section{Superconductivity}

Edited by R. D. Parks. Vol. 1: Pp. xv+664. Vol. 2: Pp. xv+665-1412. (Dekker: New York, April 1969.) Both vols. $713 s ; \$ 75$.

THere are fourteen hundred pages by thirty-three authors in this book, which is largely on the theoretical aspects of superconductivity. Most of it is written with a feeling of achievement: yet I believe that these two volumes can be appraised only in a contradictory manner. They form an excellent authoritative survey on the present state of the orthodox science of superconductivity. At the same time, they present the dismal picture that arises out of excessive inbreeding.

In the early days of quantum mechanies, when most properties of metals were beginning to be understood at least qualitatively, superconductivity formed the notorious exception. Our present understanding of superconductivity was essentially achieved in two steps: the first, in 1950, led to the formulation of a hitherto unsuspected interaction of electrons via phonons (isotope effect), and hence to a mathematical formulation of the problem. A few years later, the second step demonstrated the importance of the pair correlation of electrons. Tt indicated the manner in which the solution of the pre-

\section{The Scattering of Light and Other Electromagnetic Radiation}

By Milton Kerker. (Physical Chemistry: A Series of Monographs, No. 16.) Pp. xv + 666. (Academic Press: New York and London, August 1969.) $313 s$.

THERE were more than four hundred publications dealing with molecular weight determination by light scattering during the two years 1964-65. This fact, which was pointed out by the author of this book, shows the extent to which light scattering has become an established experimental method for the physical chemist. Apart from the relatively short review articles which have appeared from time to time, the experimentalist has had to be content with the theoretical work of Van de Hulst (Light Scattering by Small Particles) or the outdated book by Stacey (Light Scattering in Physical Chemistry). In The Scattering of Light there has become available an up to date work which will gladden the hoart of many who are engaged in light scattering.

As a physical chemist, Milton Kerker has been concerned with a host of scattering studies. In this book, he lays his experience before the reader. The book is clear, 